\title{
Young coconut juice, a potential therapeutic agent that could significantly reduce some pathologies associated with Alzheimer's disease: novel findings
}

\author{
Nisaudah Radenahmad ${ }^{1}$, Farid Saleh ${ }^{2 *}$, Kitja Sawangjaroen ${ }^{3}$, Uraporn Vongvatcharanon ${ }^{1}$, \\ Patchara Subhadhirasakul ${ }^{1}$, Wilart Rundorn ${ }^{3}$, Boonsirm Withyachumnarnkul ${ }^{4}$ and James R. Connor ${ }^{5}$ \\ ${ }^{1}$ Department of Anatomy, Faculty of Science, Prince of Songkla University, Hat Yai 90112, Thailand \\ ${ }^{2}$ Department of Anatomy, Faculty of Medicine, Kuwait University, Jabriya, PO Box 24923, Safat 13110, Kuwait \\ ${ }^{3}$ Department of Pharmacology, Faculty of Science, Prince of Songkla University, Hat Yai 90112, Thailand \\ ${ }^{4}$ Department of Anatomy, Faculty of Science, Mabidol University, Bangkok 10400, Thailand \\ ${ }^{5}$ Department of Neurosurgery, The Penn State University College of Medicine, PO Box 850, 500 University Drive Hershey, \\ Hershey, PA 17033-0850, USA
}

(Received 19 February 2010 - Revised 22 July 2010 - Accepted 27 July 2010 - First published online 30 November 2010)

\section{Abstract}

Brains from ovariectomised (ovx) rats can display features similar to those observed in menopausal women with Alzheimer's disease (AD), and oestrogen seems to play a key role. Preliminary studies on young coconut juice (YCJ) have reported the presence of oestrogen-like components in it. The aim of the study was to investigate the effects of YCJ on the AD pathological changes in the brains of ovx rats. Rat groups included sham-operated, ovx, ovx + oestradiol benzoate (EB) and ovx + YCJ. Brain sections $(4 \mu \mathrm{m})$ were taken and were immunostained with $\beta$-amyloid (A $\beta$ ) 1-42, glial fibrillary acidic protein (GFAP) (an intermediate neurofilament of astrocytes) and Tau-1 antibodies. A $\beta$ 1-42, GFAP and Tau-1 are considered as reliable biomarkers of amyloidosis, astrogliosis and tauopathy (neurofibrillary tangles), respectively, which in turn are characteristic features associated with AD. The serum oestradiol (E2) level was measured using a chemiluminescent immunoassay technique. YCJ restored the serum E2 to levels significantly $(P<0 \cdot 001)$ higher than that of the ovx group, and even that of the sham group. $\mathrm{A} \beta$ deposition was significantly $(P<0 \cdot 0001)$ reduced in the cerebral cortex of the YCJ group, as compared with the ovx group and with the sham and ovx + EB groups $(P<0 \cdot 01)$. A similar trend was observed in relation to GFAP expression in the cerebral cortex and to Tau- 1 expression in the hippocampus. This is a novel study demonstrating that YCJ could have positive future implications in the prevention and treatment of $\mathrm{AD}$ in menopausal women.

Key words: Young coconut juice: Alzheimer's disease: Menopause

Oestrogen levels tend to decrease dramatically in women during their menopausal years. Such a decrease in endogenous oestrogen has been associated with an increased risk of certain diseases such as CVD and osteoporosis ${ }^{(1)}$. It has been postulated that low oestrogen levels could be associated with an increased risk of dementia/Alzheimer's disease (AD), and, accordingly, such a relationship is biologically plausible ${ }^{(2-4)}$. Nevertheless, evidence-based data confirming such a relationship are still lacking, and, if proven, it may have major implications for the prevention or treatment of dementia and $\mathrm{AD}$ in menopausal women. We have recently reported that drinking young coconut juice (YCJ), which contains oestrogen-like ingredients, would significantly reduce some histopathological changes in the brain that are induced by inadequate levels of circulating oestrogen following ovariectomy ${ }^{(5)}$. YCJ is the juice taken from the coconut fruit when the latter is about 6 months old.

In ovariectomised (ovx) rats, oestrogen injections have been found to increase choline acetyltransferase activity in the basal forebrain and in the hippocampus ${ }^{(6,7)}$. In humans, such areas have been found to be acetylcholine deficient in patients with $\mathrm{AD}^{(2)}$. Other benefits that were reported to be associated with oestrogen include improving synapse formation on the dendritic spines of the neurons in the hippocampus, improving cerebral blood flow to the brain and improving the brain's glucose metabolism ${ }^{(3,8)}$. Oestrogen was also reported to act as an antioxidant, and it may exert an influence on the development of dementia by reducing the risk of $\mathrm{CVD}^{(2,3,8-11)}$. Some studies have

Abbreviations: A $\beta$, amyloid $\beta / \beta$-amyloid; AD, Alzheimer's disease; APP, amyloid precursor protein; E2, oestradiol; EB, E2 benzoate; GFAP, glial fibrillary acidic protein; ovx, ovariectomised; YCJ, young coconut juice. 
reported a lower prevalence and incidence of dementia and AD in menopausal women who used oestrogen replacement therapy ${ }^{(12-14)}$. Other studies have found that a higher concentration of bioavailable oestradiol (E2) was associated with a slower cognitive decline ${ }^{(15)}$. This indicates that supplementation with exogenous oestrogen may reduce the risk of dementia ${ }^{(16-18)}$.

Some characteristic features that have been reported to be present in the brains of patients with $\mathrm{AD}$ include the deposition of $\beta$-amyloid (also known as amyloid $\beta$ or $A \beta$ ), abnormal regulation of the glial fibrillary acidic protein (GFAP) and hyperphosphorylation of the microtubule-associated protein Tau- $1 . \mathrm{A} \beta$ is a peptide, and it is the main constituent of the amyloid plaques which are often observed in the brains of $\mathrm{AD}$ patients ${ }^{(19)}$. $\mathrm{A} \beta$ is formed following the sequential cleavage of the amyloid precursor protein (APP). APP can be processed by $\alpha-, \beta$ - and $\gamma$-secretases, and the $A \beta$ protein is generated following the successive action of the $\beta$ - and $\gamma$-secretases. The $\gamma$-secretase cleaves within the transmembrane region of APP, thus generating a number of isoforms ${ }^{(20)}$. The most common isoforms are $A \beta-40$ and $A \beta-42$, but $A \beta-42$ is more fibrillogenic and is thus associated with disease states. Mutations in APP associated with early-onset AD have been observed to increase the relative production of $\mathrm{A} \beta-42^{(21)}$. GFAP is an intermediate filament protein that is expressed by astrocytes and ependymal cells in the central nervous system. It is closely related to its non-epithelial family members, vimentin, desmin and peripherin, which are all involved in the structure and function of the cell's cytoskeleton. GFAP helps in maintaining astrocyte mechanical strength, as well as cellular shape, movement and communication. Phosphorylation of GFAP can occur at five different sites on the protein, including the head domain. The post-translational modification occurring at the head domain can alter the charge of the protein, resulting in disaggregation and subsequent breakdown of the filaments ${ }^{(22)}$. In neurodegenerative disorders such as $\mathrm{AD}$, an increase in the intracellular and extracellular concentrations of GFAP has been documented. Tau proteins are microtubule-associated proteins that are predominantly present in the distal axons of the neurons of the central nervous system. They promote tubulin assembly into microtubules so that they stabilise the latter. Six tau isoforms exist in the brain tissue, and they are distinguished by their number of binding domains. Phosphorylation of tau is regulated by a number of kinases. Its hyperphosphorylation can result in the selfassembly of tangles of paired helical filaments and straight filaments, known as neurofibrillary tangles, which are involved in the pathogenesis of $\mathrm{AD}^{(23)}$.

Punghmatharith ${ }^{(24)}$ used RIA techniques to demonstrate that $1 \mathrm{ml}$ of YCJ contains $2.45 \mathrm{pg}$ of $17 \beta-\mathrm{E} 2$, in addition to other sex hormone-like substances such as oestrone-3glucuronide $(280.27 \mathrm{pg})$, pregnanediol- $3 \alpha$-glucuronide $(263.27 \mathrm{pg})$, progesterone $(27 \cdot 17 \mathrm{pg})$, testosterone $(1.58 \mathrm{pg})$ and oestrone $(0.75 \mathrm{pg})$. Similarly, results from TLC showed that YCJ contained substances similar to oestrone, 17 $\beta$-E2 and $\beta$-sitosterol ${ }^{(24)}$. The author also found that subcutaneous injection of an ethereal extract of YCJ reconstituted at a dose equivalent to $7500 \mathrm{ml}$ of $\mathrm{YCJ} / \mathrm{kg}$ body weight per $\mathrm{d}$ for three consecutive days significantly increased the uterine weight of immature rats.

In the present study, we used YCJ to investigate its possible beneficial effect on the brains of ovx rats, an animal model that mimics AD in menopausal women. In particular, we examined the brains of these rats for some characteristic features of $\mathrm{AD}$, namely amyloidosis, astrogliosis and tauopathy (neurofibrillary tangles), using the associated markers A $\beta$ 1-42, GFAP and Tau-1, respectively.

\section{Materials and methods}

\section{Plant material}

A complete description of YCJ, including its preparation and administration, is provided in a recent publication ${ }^{(25)}$ Briefly, YCJ (Cocos nucifera L., Arecaceae) was collected from Namnoi District, Hat Yai, Songkhla, Thailand. It was then pooled and dried using a specialised lyophiliser (MillRock Technology, Kingston, NY, USA) at the Department of Pharmacognosy and Pharmaceutical Botany, Prince of Songkla University ${ }^{(25)}$. The powder formed was kept at $-30^{\circ} \mathrm{C}$. It was freshly reconstituted and prepared for oral intake every day.

\section{Animals}

The study was approved by the Committee on Animal Care and was carried out in accordance with the Guiding Principles for the Care and Use of Research Animals promulgated by Prince of Songkla University. All animals used were adult 4-month-old female Wistar rats weighing 270 (sem 2) g. The animals were housed in a controlled environment at $25 \pm 1^{\circ} \mathrm{C}$ on an illumination schedule of a $12 \mathrm{~h}$ light $-12 \mathrm{~h}$ dark cycle. Rats had unrestricted access to standard pellet food and water.

\section{Experimental design}

There were four groups ( $n$ 10) included in the present study: sham-operated rats; ovx rats; ovx rats injected intraperitoneally with exogenous oestrogen $(2.5 \mu \mathrm{g} / \mathrm{kg}$ body weight of E2 benzoate, EB) twice a week for 4 weeks; ovx rats which received YCJ ( $100 \mathrm{ml} / \mathrm{kg}$ body weight per d) for 4 weeks. The dose of EB and YCJ in the present study was based on the one reported in our earlier study and in which dose standardisation and optimal administration were set $^{(25)}$. In the present study, the administration of $\mathrm{EB}$ and YCJ was started 4 weeks after ovariectomy was performed. Rats belonging to the first and second groups received Milli Q water (deionised, but further distilled water) instead. 


\section{Immunohistochemistry}

Tissue samples from the cerebral cortex pertaining to the temporal, parietal and occipital lobes, and from the hippocampus were processed into paraffin blocks, and thirteen $4 \mu \mathrm{m}$ sections were collected from each block and mounted on 3-aminopropyltriethoxysilane (Sigma, Poole, Dorset, UK)-coated slides. Anatomical orientation to the rat brain was facilitated using a rat brain anatomy atlas $^{(26)}$. The first two sections were stained with cresyl violet, and were used for light microscopy examination and anatomical orientation. Three of the remaining eleven sections were immunostained with the purified rabbit polyclonal anti-A $\beta$ 1-42 antibody (AB5078P; Chemicon International, Temecula, CA, USA), another three sections were immunostained with the mouse antiGFAP monoclonal antibody (MAB3402; Chemicon International) and three other sections were immunostained with the mouse anti-Tau-1 monoclonal antibody (MAB3420; Chemicon International). The remaining two sections were used as negative controls, whereby the primary antibody was omitted and replaced by Tris-buffered saline. Positive controls were cortical and hippocampal brain sections known to be positive for the above antibodies.

The immunostaining technique was as follows. Sections were left on a hot plate at $37^{\circ} \mathrm{C}$ overnight. This was followed by passing the sections through serial steps of fresh xylene and alcohol gradients. The sections were then left in distilled water for $10 \mathrm{~min}$ before antigen retrieval by microwave for half an hour was performed (0.01\% sodium citrate antigen retrieval solution; $650 \mathrm{~W}$ ). The sections were then allowed to cool down at room temperature for $15 \mathrm{~min}$, followed by washing with Tris-buffered saline and incubation for $10 \mathrm{~min}$ with $0.3 \% \mathrm{H}_{2} \mathrm{O}_{2}$ in methanol to quench any endogenous peroxidase activity. In the case of staining for $\mathrm{A} \beta$ 1-42, the sections were also pretreated for $30 \mathrm{~min}$ with $80 \%$ formic acid at room temperature. Having accomplished the preparatory phase, we then incubated the sections with the above primary antibodies for $30 \mathrm{~min}$ in a humidified chamber, washed them with Tris-buffered saline and then incubated them with the secondary and tertiary antibodies with frequent Tris-buffered saline washes in between. The procedure was followed according to the steps provided with the ABC kit used (Vectastain ${ }^{\circledR}$ Elite ABC kit; Vector Laboratories, Burlingame, CA, USA). The substrate chromogen ( 1 min incubation time) used in the present study was diaminobenzidene enhanced by the addition of a Ni solution from the staining kit (Vector Laboratories). Sections were then counterstained with Meyer's haematoxylin for $5 \mathrm{~s}$ and cover slipped.

\section{Image analysis}

Measurement of the immunostaining was performed by a blinded observer using an image analysis system. The image analysis system consisted of an observer-interactive computerised image analysis (Samba microscopic image processor; Samba Technologies, Meylan, France). This system is fitted with a standard axioplan microscope with an automated stage (Carl Zeiss, Oberkochen, Germany), allowing a precise location of a particular field through the $X Y Z$ axis plotting, a colour video camera (Sony Corporation, Tokyo, Japan), an image analysis processor (Matrox, Montreal, QC, Canada) and a personal computer (Pentium 2, $166 \mathrm{MHz}$ processor; Intel, Santa Clara, CA, USA). Counting was done in ten random fields at $400 \times$ magnification. Readings from the three sections pertaining to each antibody were then added and the average was determined. Random selection of the fields was achieved using a computer-generated list of random numbers (Excel version 5.0). The means with their standard errors were used to compare the four groups.

\section{Serum oestradiol}

All the rats were killed at the end of the treatment period, and their serum was collected through a carotid catheter for E2 measurement using the chemiluminescent immunoassay technique (CIA kit LKE2 10 261; DPC, Caernarfon, Gwynedd, UK).

\section{Statistical analysis}

Statistical analysis was performed using Kruskal-Wallis and Mann-Whitney $U$ tests available in the statistical program SPSS version 13.0 (SPSS, Inc., Chicago, IL, USA). Altman's nomogram was used for sample size calculations. Random selection of the microscopic fields was achieved using a computer-generated list of random numbers (Excel version 5.0). Results were reported as the means with their standard errors. $P<0.05$ was considered statistically significant.

\section{Results}

\section{Serum oestradiol level}

Mean serum E2 levels were 46 (SEM 2), 24 (SEM 1), 56 (SEM 3) and 66 (SEM 1) $\mu \mathrm{g} / \mathrm{ml}$ in the sham, ovx, ovx $+\mathrm{EB}$ and ovx + YCJ groups, respectively. Such results demonstrate that administration of either EB or YCJ for 4 weeks restored the serum E2 to levels significantly $(P<0.001)$ higher than that of the ovx group, and even to a higher level as compared with the one observed in the sham group. When comparison was performed between the serum E2 level in the ovx + EB group and the ovx + YCJ group, no significant difference was observed. Our attempt to correlate the serum E2 level in the various cortical brain regions with the expression of A $\beta 1-42$ and GFAP, and in the various areas of the hippocampus with the expression of Tau-1, revealed that there was a negative correlation 
( $r-0 \cdot 1,-0 \cdot 13$ and $-0 \cdot 12$, respectively). This indicates that the higher the serum E2 level, the lesser the pathology.

\section{$\beta$-Amyloid 1-42}

In all the four groups studied, $A \beta 1-42$ was observed in the cell bodies, dendrites and axons of a subset of neocortical pyramidal neurons having a triangular cell body and prominent dendrites. In some areas, $A \beta 1-42$ was present in neurons having a polygonal shape identified as large stellate cells.

The distribution of $\mathrm{A} \beta 1-42$ positive neurons was uneven throughout the cortex. The majority of these neurons were located in layer V. Smaller, less numerous and weakly stained pyramidal cells were visualised in layer
III. A $\beta 1-42$ was also detected in the choroid plexus. Amyloid angiopathy was observed in the arteries, but none was detected in the veins. A $\beta$ deposition was significantly $(P<0.0001)$ reduced in the cerebral cortex of the occipital (4.4 (SEM 1.2)), parietal (2.9 (SEM 1.5)) and temporal (1 (SEM $0 \cdot 8))$ lobes of the YCJ-treated group, as compared with the ovx group (15 (sem 2), 13.3 (SEM 1.9) and 10.3 (SEM 1.7), respectively) (Fig. 1). Surprisingly, such a significant $(P<0.01)$ reduction was also observed when the ovx + YCJ group was compared with the sham group (6.8 (SEM 1.9), $5 \cdot 3$ (SEM 1.4) and 4.4 (SEM 0.9), respectively) and with the ovx + EB group (8.5 (SEM 2), $7 \cdot 5$ (SEM 1.7) and 5.3 (SEM 1.5 ), respectively). This was especially evident in the temporal lobe.
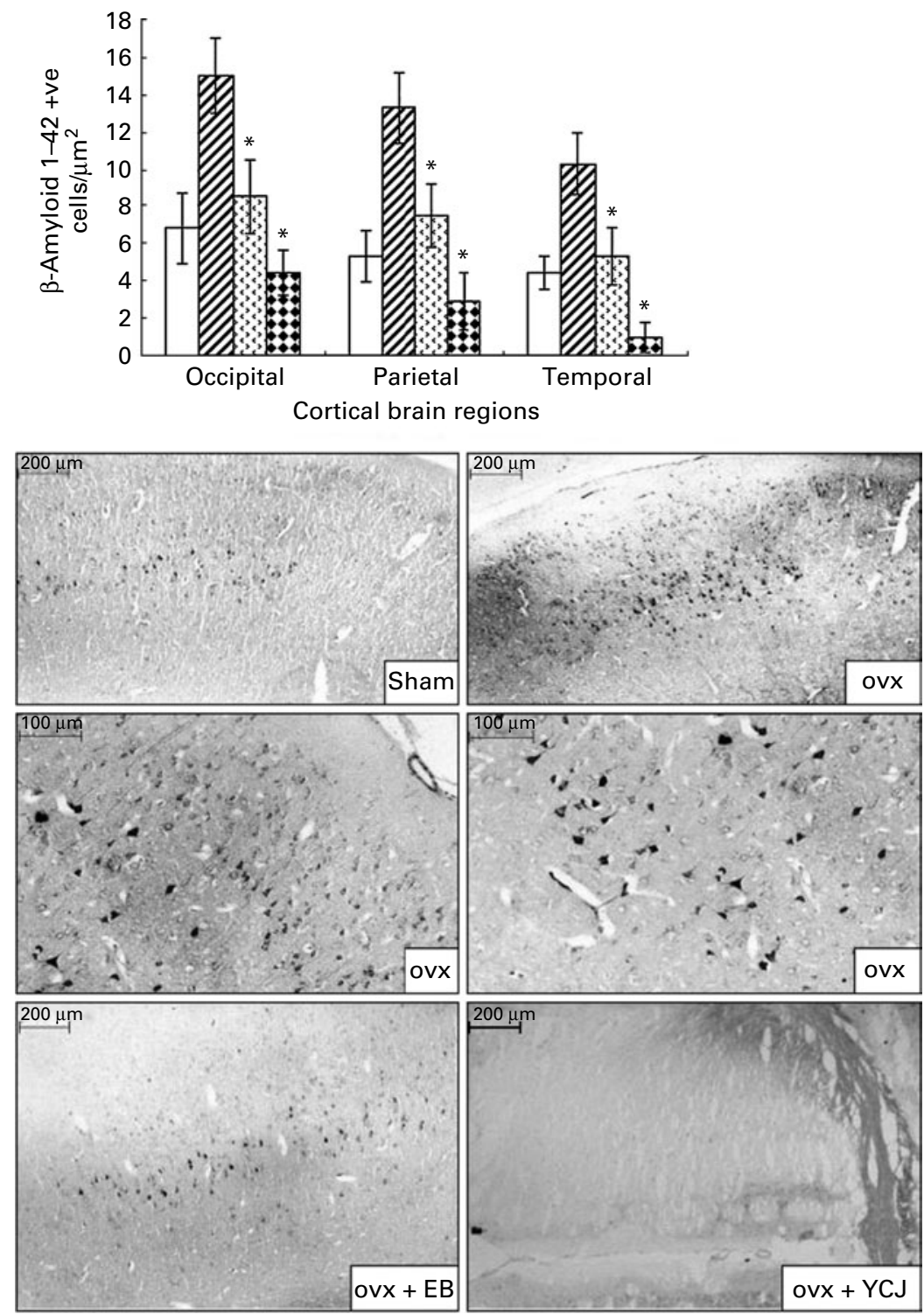

Fig. 1. Expression of $\beta$-amyloid 1-42 in the cerebral cortex of the occipital, parietal and temporal lobes. Each group consisted of ten rats. Data are expressed as means with their standard errors. ovx, Ovariectomy; EB, oestradiol benzoate; YCJ, young coconut juice. $\square$, Sham; $\mathbf{Z}$, ovx; $匚$, ovx + EB; $\mathbf{E}$, ovx $+\mathrm{YCJ}$. ${ }^{\star} \mathrm{Mean}$ values were significantly different $(P<0.05)$. 


\section{Glial fibrillary acidic protein}

GFAP was detected exclusively in astrocytes with obvious astrocytic feet attached to the blood vessels. It was found in the six layers of the cerebral cortex, but mainly in layers II-VI.

Similar to $\mathrm{A} \beta$, administration of $\mathrm{YCJ}$ resulted in a significant $(P<0.0001)$ reduction in GFAP in the occipital (14 (SEM 0.9)), parietal (12 (SEM 0.6)) and temporal (10 (SEM 0.5)) lobes, as compared with the ovx group (67 (sEm 1.2), 57 (SEM 1.8) and 53 (SEM 2), respectively) (Fig. 2). In fact, YCJ was able to reduce GFAP to levels which are significantly $(P<0 \cdot 01)$ below those observed in the sham group (32 (SEM 0.6), 29 (SEM 0.4) and 30 (SEM 0.8), respectively) and in the ovx + EB group (40 (SEM 1.1), 34 (SEM 1.4) and 35
(SEm 1.6), respectively) ( $P<0 \cdot 001)$. The absolute reduction was again observed in the temporal lobe.

\section{Tau-1}

The ovariectomy-induced histopathological changes were more prominent in the hippocampus in relation to the neurofibrillary tangles. A significantly $(P<0.0001)$ higher expression of Tau-1 was observed in the CA1 (25.4 (SEM 3.6)), CA2 (SEM 27.8 (2.7)) and CA3 (20.7 (SEM 1.9)) areas of the hippocampus of the ovx group, as compared with the sham group (2.4 (SEM 0.4), $7 \cdot 6$ (SEM 0.9) and $2 \cdot 1$ (SEM $1 \cdot 1$ ), respectively) (Fig. 3). The intraperitoneal injection of EB for 4 weeks was able to reverse such pathology to levels close (especially in CA3) to the ones seen in the
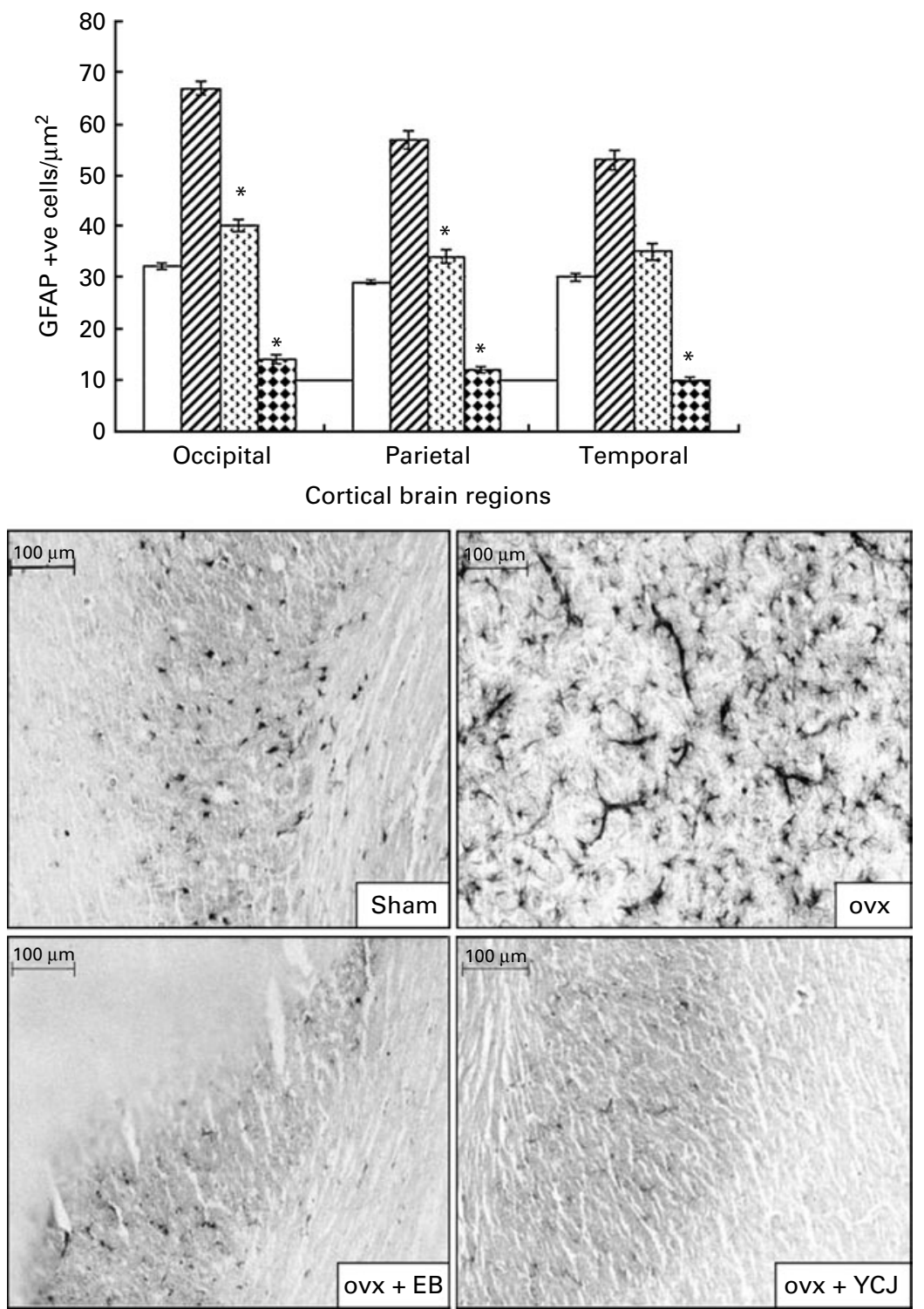

Fig. 2. Expression of glial fibrillary acidic protein in the cerebral cortex of the occipital, parietal and temporal lobes. Each group consisted of ten rats. Data are expressed as the means with their standard errors. ovx, Ovariectomy; EB, oestradiol benzoate; YCJ, young coconut juice. $\square$, Sham; $\boldsymbol{Z}$, ovx; $匚$, ovx $+E B ;$; ovx + YCJ. * Mean values were significantly different $(P<0.05)$. 
sham group. Interestingly, the results observed in the group that received YCJ for 4 weeks were better than those obtained with EB. Here, YCJ was able to reduce the expression of Tau-1 to levels less than the ones observed in the sham group in the CA1 (2 (SEM 0.5)) and CA2 (4.1 (sem 0.6)) areas, and to a level almost equal to the sham group in the CA3 (2.3 (SEm 0.9)) area. Moreover, a significant difference was observed when comparison was done between the ovx + YCJ and the ovx-EB groups in the CA1 (2 (SEM 0.5) v. 4.6 (SEM 1.5); $P<0.01)$ and the CA2 (4.1 (sem 0.6) v. $11.7($ sem 1.4$) ; P<0.001)$ areas.

\section{Discussion}

$\mathrm{AD}$ is recognised as a worldwide problem affecting the quality of life of millions of people during their elderly years and consuming a significant amount of the governments' health care budgets in developed countries. Identification of factors that influence the onset and progression of the disease has been the focus of scientists and clinicians over the years in an attempt to come up with efficient preventive measures and treatments. Among the predisposing factors to $\mathrm{AD}$ in menopausal women, oestrogen seems to play an important role. This was elaborated in studies where hormone replacement therapy had significantly delayed or reduced the risk of developing $\operatorname{AD}^{(27,28)}$.

Identified as a protein misfolding disease, $\mathrm{AD}$ has been characterised by the accumulation of abnormally folded $\mathrm{A} \beta$, GFAP and tau proteins in the brain ${ }^{(29)}$. A $\beta$ plaques consist of small peptide fragments produced by abnormal proteolysis of a larger protein called $\mathrm{APP}^{(30)}$. Normally, APP is
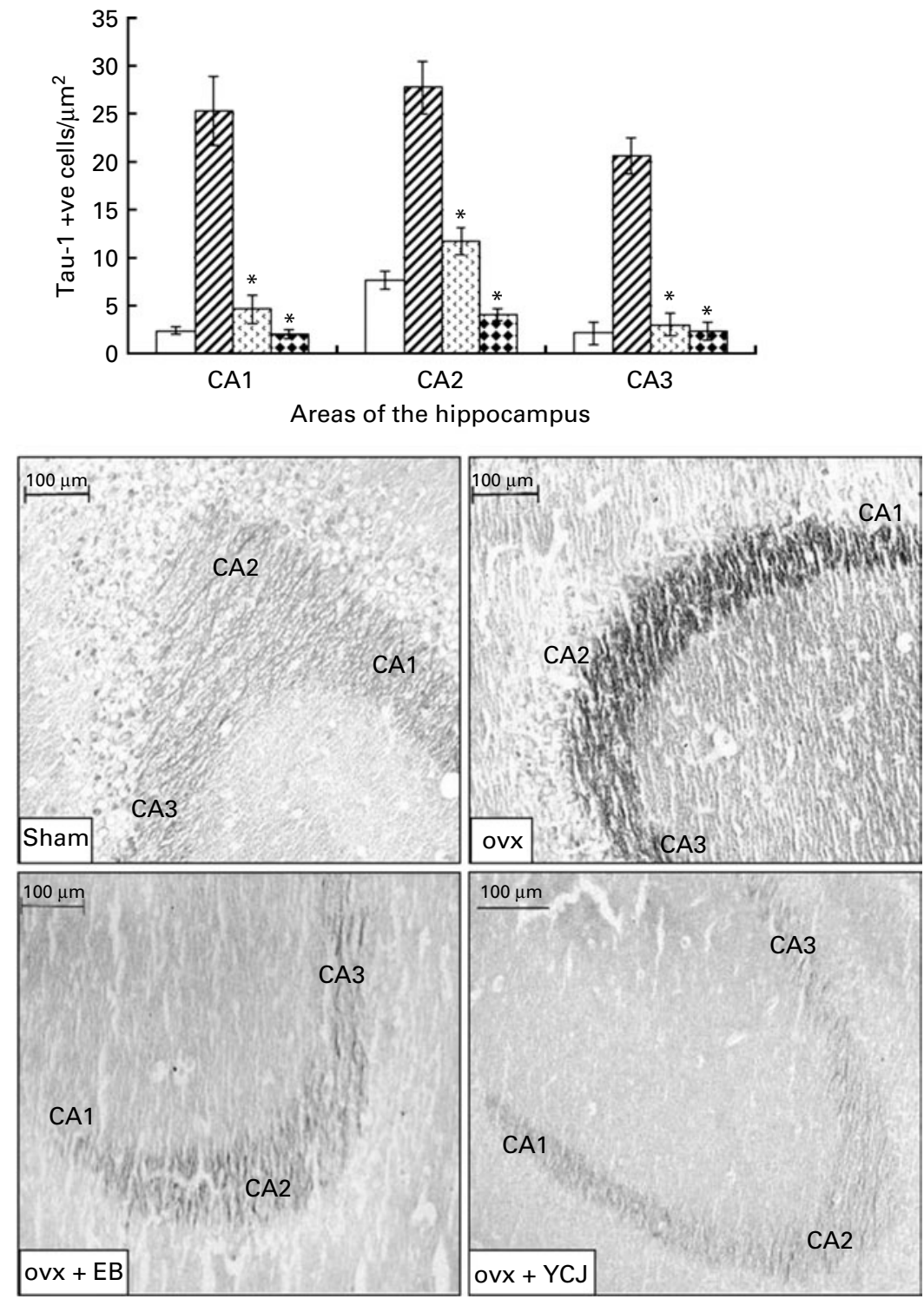

Fig. 3. Expression of Tau-1 in the CA1, CA2 and CA3 areas of the hippocampus. Each group consisted of ten rats. Data are expressed as means with their stan-

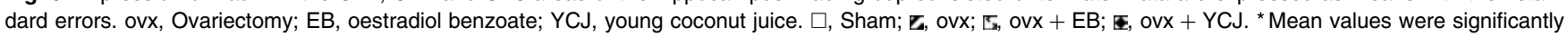
different $(P<0.05)$. 
a transmembrane protein that penetrates through the neuron membrane, and it plays a critical role in neuronal survival, post-injury repair and growth ${ }^{(31-33)}$. AD has also been associated with abnormal aggregation of the GFAP and tau proteins resulting from their abnormal phosphorylation. Normally, each neuron has a supporting cytoskeleton consisting of microtubules that act as pathways for molecules and nutrients between the neuronal cell body and the terminal ends of the axon. Such microtubules are regularly stabilised by the tau protein when the latter is phosphorylated.

However, the hyperphosphorylation of this protein, which takes place in $\mathrm{AD}$, results in the pairing of tau with other threads, and thus forming neurofibrillary tangles. Such tangles, in turn, disrupt and disintegrate the pathways between the cell body and the terminal axon ${ }^{(23)}$. In addition to $A \beta$ and tau, abnormal deposition of GFAP is another feature observed in the brain of AD patients. GFAP is an intermediate filament protein, which normally maintains the cytoskeleton of the neurons' supporting cells in the central nervous system, namely the astrocytes and the ependymal cells. In $\mathrm{AD}$, phosphorylation of the head domain of the GFAP protein and the subsequent post-translational modification of this domain alter the charge of the protein, resulting in disaggregation and breakdown of the filaments ${ }^{(22)}$. Subsequently, an increase in the intracellular and extracellular concentrations of GFAP becomes evident.

The histopathological changes described earlier in the brains of $\mathrm{AD}$ patients are also observed in some animal models, such as in the brains of transgenic mice and in the brains of female rats in which the ovaries were removed (ovx rats) ${ }^{(34-36)}$. Accordingly, in the present study we used, the ovx rat model to investigate the ability of YCJ, which is advocated to contain oestrogen-like hormones, to reduce some of the histopathological changes seen in $\mathrm{AD}$, namely the abnormal deposition of $\mathrm{A} \beta$, GFAP and Tau-1. The present results showed that administration of YCJ for 4 weeks following a 4-week period of ovariectomy was able to reduce the brain pathologies seen in the ovx group which did not receive YCJ. The difference between the two groups was very prominent in the temporal, parietal and occipital cortical brain regions in relation to $\mathrm{A} \beta$ and GFAP, and in the CA1, CA2 and CA3 areas of the hippocampus in relation to Tau-1. Moreover, it was interesting to observe that YCJ had even better effects in such reduction, as compared with $\mathrm{EB}$ which was given to the ovx group for the same duration as YCJ. Another important observation was that the brain of the rats receiving YCJ had significantly less pathology, as compared with the sham group. Again, this was evident in all the cortical brain regions we examined, and in the CA2 area of the hippocampus. Our group is currently investigating the reasons as to why the results (data not shown, but to be reported in a separate publication) obtained from the cortical brain regions with Tau-1 were inconsistent and did not show any trend, and as to why such inconsistency and lack of trend were observed with $A \beta$ 1-42 and GFAP in the hippocampus. The findings which we observed in the occipital region of the brain in relation to $A \beta 1-42$ and GFAP are interesting, since such histopathological changes have not been described in this region of the brain according to our knowledge. Such an observation requires further investigation. Another interesting observation in the present study was that the serum E2 level was inversely proportional to the pathology present in the brain of the ovx rats, and this seems to add more evidence on the role of hormonal imbalance in the pathology of $\mathrm{AD}$ in menopausal women. Our future plan is to screen the brain of the ovx rats for the hormonal level of E2, as well as to search for E2 receptors in the various constituents of such brain, namely neurons, supporting cells and extracellular matrix.

Several reports have elucidated that cerebral amyloid angiopathy could be a direct cause of dementia ${ }^{(37,38)}$. Alternatively, cerebral amyloid angiopathy may indirectly affect cognition by impairing cerebral perfusion, leading to infarction or diffuse ischaemic injury ${ }^{(39)}$. In the present study, $A \beta 1-42$ deposition was detected in the meningeal arteries and in the parenchymal capillaries of the grey matter. In contrast, none of such deposition was observed in the cerebral venous system. This is yet another interesting observation in the present study, and it will be investigated by our group.

The complete chemical ingredient of YCJ is still being identified. It has been reported so far that YCJ contains $\beta$-sitosterol (58\% of the total composition of $1 \mathrm{ml}$ of $\mathrm{YCJ}$ ), in addition to other sterols, such as stigmastatrienol, stigmasterol and fucosterol and $\alpha$-spinasterol ${ }^{(24)}$. $\beta$-Sitosterol is structurally related to animal cholesterol and can possibly act as a precursor of sex steroids ${ }^{(40)}$. Salah et al. ${ }^{(41)}$ found that a methanol extract of Ruellia praetermissa Sceinf. Ex. Lindau (Acanthaceae) had an oestrogenic effect on the uterus and gestation in rats, and postulated that this could be related to the presence of $\beta$-sitosterol, stigmasterol and flavonoids. In the present study, whether $\beta$-sitosterol and stigmasterol (plant sterols known to be involved in the synthesis of steroid hormones in vivo) could be responsible for the strong oestrogenic effect of YCJ by facilitating the synthesis of endogenous oestrogens remains to be examined by our group. The findings from such an investigation could partially provide an explanation to the observation reported in the present study, namely the superior results obtained with YCJ, as compared with EB. More explanation for the superiority of YCJ in the present study could be obtained when the complete chemical ingredient of YCJ is identified.

\section{Conclusion}

The present study has reported some novel data demonstrating that biomarkers for $\mathrm{AD}$ in the brains of living mammals are influenced by compounds derived from a plant 
with possible oestrogen-like ingredients, namely from YCJ. Accordingly, the ovx-rat model could be a useful animal model for evaluating the impact of oestrogen derivatives, oestrogen-like compounds and selective oestrogen receptor modulators on the biomarkers of $\mathrm{AD}$ in vivo. Moreover, we present evidence that prolonged ovariectomy is associated with a significant increase in brain pathology, which can be reversed following the intake of YCJ. The latter could hopefully have positive future implications in the prevention and treatment of neurodegenerative pathologies in menopausal women.

\section{Acknowledgements}

The authors confirm that there are no conflicts of interest. The present study was funded by the Department of Anatomy, Faculty of Science, Prince of Songkla University and the Thailand Research Fund. N. R. and F. S. contributed to the experimental design and analysis. N. R. also contributed to the experimental analysis, and F. S. to writing up the manuscript as well as its submission and following up on such submission. K. S. and W. R. contributed to the isolation and purification of YCJ. U. V., P. S. and B. W. assisted in the experimental analysis. J. R. C. assisted in the final editing of the manuscript.

\section{References}

1. Christiansen C \& Lindsay R (1990) Estrogen, bone loss and preservation. Osteoporosis Int 1, 7-13.

2. Gibbs RB \& Aggarwal P (1998) Estrogen and basal forebrain cholinergic neurons: implications for brain aging and Alzheimer's disease-related cognitive decline. Horm Behav 34, 98-111.

3. McEwen BS \& Alves SE (1999) Estrogen actions in the central nervous system. Endocr Rev 20, 279-307.

4. Solerte SB, Fioravanti M, Racchi M, et al. (1999) Menopause and estrogen deficiency as a risk factor in dementing illness: hypothesis on the biological basis. Maturitas 31, 95-101.

5. Radenahmad N, Saleh F, Sawangjaroen K, et al. (2009) Young coconut juice significantly reduces histopathological changes in the brain that is induced by hormonal imbalance: a possible implication to postmenopausal women. Histol Histopathol 24, 667-674.

6. Gibbs RB (1996) Expression of estrogen receptor-like immunoreactivity by different subgroups of basal forebrain cholinergic neurons in gonadectomized male and female rats. Brain Res 720, 61-68.

7. Gibbs RB (1997) Effects of estrogen on basal forebrain cholinergic neurons vary as a function of dose and duration of treatment. Brain Res 757, 10-16.

8. Monk D \& Brodaty H (2000) Use of estrogens for the prevention and treatment of Alzheimer's disease. Dement Geriatr $\operatorname{Cogn}$ 11, 1-10.

9. Breteler MM, Claus JJ, Grobbee DE, et al. (1994) Cardiovascular disease and distribution of cognitive function in elderly people: the Rotterdam Study. Br Med J 308, 1604-1608.

10. Birge SJ (1996) Is there a role for estrogen replacement therapy in the prevention and treatment of dementia? J Am Geriatr Soc 44, 865-870.
11. Yaffe K, Sawaya G, Lieberburg I, et al. (1998) Estrogen therapy in postmenopausal women: effects on cognitive function and dementia. J Am Med Assoc 279, 688-695.

12. Henderson VW (1997) Estrogen, cognition, and a woman's risk of Alzheimer's disease. Am J Med 103, 11S-18S.

13. Bhavnani BR (2003) Estrogens and menopause: pharmacology of conjugated equine estrogens and their potential role in the prevention of neurodegenerative diseases such as Alzheimer's. J Steroid Biochem Mol Biol 85, 473-482.

14. Casadesus G, Rolston RK, Webber KM, et al. (2008) Menopause, estrogen, and gonadotropins in Alzheimer's disease. Adv Clin Chem 45, 139-153.

15. Yaffe K, Lui LY, Grady D, et al. (2000) Cognitive decline in women in relation to non-protein-bound estradiol concentration. Lancet 356, 708-712.

16. Paganini-Hill A \& Henderson VW (1994) Estrogen deficiency and risk of Alzheimer's disease in women. Am J Epidemiol 140, 256-261.

17. Paganini-Hill A \& Henderson VW (1996) Estrogen replacement therapy and risk of Alzheimer disease. Arch Intern Med 156, 2213-2217.

18. Waring SC, Rocca WA, Petersen RC, et al. (1999) Postmenopausal estrogen replacement therapy and risk of AD: a population-basic study. Neurology 52, 965-970.

19. Shankar GM, Li S, Mehta TH, et al. (2008) Amyloid-protein dimers isolated directly from Alzheimer's brains impair synaptic plasticity and memory. Nat Med 14, 837 .

20. Hartmann T, Bieger SC \& Brühl B (1997) Distinct sites of intracellular production for Alzheimer's disease A $\beta 40 / 42$ amyloid peptides. Nat Med 3, 1016-1020.

21. Yin YI, Bassit B, Zhu L, et al. (2007) $\gamma$-Secretase substrate concentration modulates the $\mathrm{A} \beta 42 / \mathrm{A} \beta 40$ ratio: implications for Alzheimer's disease. J Biol Chem 282, 23639-23644.

22. Inagaki M, Gonda Y, Nishizawa K, et al. (1990) Phosphorylation sites linked to glial filament disassembly in vitro locate in a non-alpha-helical head domain. J Biol Chem 265, $4722-4729$.

23. Hernández F \& Avila J (2007) Tauopathies. Cell Mol Life Sci 64, 2219-2233.

24. Punghmatharith B (1988) Sex hormone-like substances in young coconut juice and their effects on uterine growth in rats. Songklanakarin J Sci Tech 10, 221-226.

25. Radenahmad N, Vongvatcharanon U, Withyachumnarnkul B, et al. (2006) Serum levels of $17 \beta$-estradiol in ovariectomized rats fed young-coconut juice and its effect on wound healing. Songklanakarin J Sci Tech 28, 897-910.

26. Paxinos G \& Watson C (1986) Stereotaxic coordinates. In The Rat Brain, 2nd ed., pp. 38-89 [G Paxinos and C Watsons, editors]. San Diego, CA: Academic Press, Inc.

27. Tang MX, Jacobs D, Stern Y, et al. (1996) Effect of oestrogen during menopause on risk and age at onset of Alzheimer's disease. Lancet 348, 429-432.

28. Melton L (2000) Sex is all in the brain: report of a Novartis Foundation Symposium on the neuronal and cognitive effects of oestrogens. Trends Endocrinol Metab 11, 69-71.

29. Hashimoto M, Rockenstein E, Crews L, et al. (2003) Role of protein aggregation in mitochondrial dysfunction and neurodegeneration in Alzheimer's and Parkinson's diseases. Neuromolecular Med 4, 21-36.

30. Selkoe DJ (1999) Translating cell biology into therapeutic advances in Alzheimer's disease. Nature 399, A23-A31.

31. Turner PR, O'Connor K, Tate WP, et al. (2003) Roles of amyloid precursor protein and its fragments in regulating neural activity, plasticity and memory. Prog Neurobiol 70, 1-32.

32. Hooper NM (2005) Roles of proteolysis and lipid rafts in the processing of the amyloid precursor protein and prion protein. Biochem Soc Trans 33, 335-338. 
33. Priller C, Bauer T, Mitteregger G, et al. (2006) Synapse formation and function is modulated by the amyloid precursor protein. J Neurosci 26, 7212-7221.

34. Chambers CB, Sigurdsson EM, Hejna MJ, et al. (2000) Amyloid- $\beta$ injection in rat amygdala alters tau protein but not mRNA expression. Exp Neurol 162, 158-170.

35. Probst P, Gotz J, Wi Ederhold KH, et al. (2000) Axonopathy and amyopathy in mice transgenic for human four-repeat tau protein. Acta Neuropathol 99, 469-481.

36. Gotz J (2001) Tau and transgenic animal models. Brain Res 35, 266-286.

37. Calhoun ME, Burgermeister P, Phinney AL, et al. (1999) Neuronal overexpression of mutant amyloid precursor protein results in prominent deposition of cerebrovascular amyloid. Proc Natl Acad Sci US A 96, 14088-14093.
38. Van Dorpe J, Smeijers L, Dewachter I, et al. (2000) Prominent cerebral amyloid angiopathy in transgenic mice overexpression the London mutant of human APP in neurons. Am J Pathol 157, 1283-1298.

39. Cadavid D, Mena H, Koeller K, et al. (2000) Cerebral beta amyloid angiopathy is a risk factor for cerebral ischemic infarction. A case control study in human brain biopsies. $J$ Neuropathol Exp Neurol 52, 702-708.

40. Moghadasian MH (2000) Pharmacological properties of plant sterols in vivo and in vitro observations. Life Sci $\mathbf{6 7}$, 605-615.

41. Salah AM, Gathumbi J, Vierling W, et al. (2002) Estrogenic and cholinergic properties of the methanol extract of Ruellia praetermissa Sceinf. ex. Lindau (Acanthaceae) in female rats. Phytomedicine 9, 52-55. 